\title{
Research on Bryophyte Landscape Design
}

\author{
Chunnong Li \\ College of landscape architecture \\ Sichuan Agricultural University \\ Chengdu, China 611130
}

\author{
Hao Tang \\ College of Environmental Sciences \\ Sichuan Agricultural University \\ Chengdu China 611130 \\ Keling Li \\ College of Fine Arts \\ Sichuan Normal University \\ Chengdu China 610066
}

\author{
Tao Jiang \\ College of Landscape Architecture \\ Sichuan Agricultural University \\ Chengdu China 611130 \\ Xiaofang $\mathrm{Yu}^{*}$ \\ College of Landscape Architecture \\ Sichuan Agricultural University \\ Chengdu China 611130
}

\begin{abstract}
Bryophyte is a very important category in the plant community. By using the field survey and literature review method, the paper focuses on the investigation of bryophyte landscape status. The main research results are as follows: (1) putting forward three principles of bryophytes in landscape design, the scientific principle, cultural principle and artistic principle. (2)illustrating the analysis and composition of bryophytes in landscape design, and applying the expression idea and methods of dot, line, plane and bulk of bryophytes in different plant landscape creations. (3)presenting the match method and recommendation modes of bryophytes with other landscape elements. The match mode of native bryophytes includes thuidium cymbifolium - zoysia japonica - ficus virens, or liverworts - sweet-scented osmanthus trees - rhododendrons, or polytrichum commune - funaria hygrometrica - leucobryum neilgherrense etc.
\end{abstract}

Keywords-bryophytes; landscape design; principle; landscape elements

\section{INTRODUCTION}

The bryophyte is an advanced group of aquatic plants transiting to the terrestrial plants. According to related statistics, there are a total of 23000 kinds of bryophytes in the world. The diversity of Chinese bryophytes is in the front rank of the world. We have 125 families, 572 genera and more than 3460 species of bryophytes. Among them, there are 58 families, 151 genera and 960 species of liverworts, and 67 families, 421 genera and more than 2500 species of mosses. They have the characteristic of wide varieties, diverse ecological categories, complex composition of regional series and many peculiar genus-species [1-4]. However, as an important part of biodiversity in nature, the bryophyte is often neglected by the garden landscape in our country. The

Fund Project: Project of Sichuan Provincial Department of Education (13ZB0295)

*Corresponding author: Ph. D. \& Associate Professor Yu Xiaofang, mainly engaged in the research of the ecological application of landscape plants. E-mail: xiaofangyu@sicau.edu.cn. successful application of bryophytes in garden landscape in Japan and other countries and regions proved that the bryophytes have a huge application space in the garden landscape.

The rock garden in Ryoanji Temple, built in 15th century in Youjing District, Jingdu City, is the most famous garden boutique in Japan. The rock garden design used white sand, brown stone and moss as subjects. The rock garden creates an atmosphere reflecting Zen thoughts, and it is a representative of abstract beauty. Since 1997, Nanjing Zhongshan Botanical Garden has attempted to apply bryophytes in garden design in the mode of specialized bryophytes garden. It used some bryophytes as theme plant materials and matched with rock and water in certain scope [5]. In 2006, Jiao Yunhong concluded: bryophyte garden refers to the botanical garden with bryophytes as subject plant materials, combined with gardening elements, such as rocks, waterscape and trees, using bryophytes as dominant species; at same time, it follows the law of ecology and landscape art design principles. It fully shows the green color beauty of the bryophytes [6]. Later in 2009, Zhou Zhijing simply classified and explained the application of bryophytes for the first time. She divided the application of bryophytes into 9 types, including specialized bryophytes garden, bonsai and indoor garden [7]. In 2010, under the strong support of the Shenzhen Municipal Urban Management Bureau, the Fairy Lake Botanical Garden has built a special artificial breeding bryophyte production nursery. Through several times of the field investigations and introductions to the southern area, researchers have successfully applied the piece planting method, plant division method, budding division method, container cultivation method, natural inoculation method and many other artificial breeding methods, and screened some artificial breeding bryophyte species suitable for Shenzhen. At present, the artificial production of bryophyte has begun to take shape. The 
application of bryophytes in garden landscape is in the exploration stage. Some have gained good effect, such as bryophyte bonsai, bryophyte vase garden and bryophyte ornament. China started late in the research of this field, but through gradual accumulation of experience, we have been making full use of rich bryophyte resources, and strengthening the application of bryophytes in garden landscape. It enriches elements for garden landscape, and diversifies urban garden biont[8]. The Bryophyte Garden in Daekwon Park in Canada Quebec has showed the beauty of bryophytes with sinuous composition, three-dimensional structure and decorative screen on the basis of modern style. According to reports, Indonesia opened the world's largest bryophyte theme park in the world in March 2012 - the Cibodas Bryophyte Garden affiliated to the Cibodas Botanical Garden.

Only a few documents have ever recorded the materials related to design methods of bryophytes. Chen Bangjie in 1963 proposed modern garden generally pursued the layering sense and mass sense of plants to form an artificial landscape similar to the natural vegetation landscape. If we can cultivate bryophytes in large area, we can get a viewing effect similar to lawn. Compared with an ordinary lawn, bryophytes generally have very few pests and diseases, and are not susceptible to weed invasion. And it only needs a low intensity of mechanized pruning [9]. Wang Qing (in 1999) thought the ornamental value of bryophytes is the highest when they develop into a single community. And due to planting conditions and other reasons, it is difficult for bryophytes to develop into multi-community, so that it is suggested to develop single community in bryophyte design [10]. Chen Binghong (in 2013) thought that due to the evergreen quality of bryophytes, they could be landscape alone, or could formed ornamental landscape with other herbs and woody plants. In garden design, we can use bryophytes to decorated rocks and bonsai, or even to create landscape or make garden alone [11]. And about design methods of the specialized bryophyte garden, Sun Junfeng also gave his own understanding. At the beginning of the construction of the specialized bryophyte garden, we should pay attention to the protection of natural resources, adjust our methods to local conditions, and highlight local characteristics and special species resources, and not pick in excess. In plant landscaping, the simulation of natural bryophyte communities should be "very like". We shouldn't only pursue the expansion of large cultivated area [12]. The coverage of natural bryophyte communities generally is very vast, so the landscape has a very shocking effect. For artificial bryophyte garden, we should highlight the unique originality and charm of the garden with innovative design.

To sum up, our exploration and research on the bryophyte landscape is not complete and thorough. So, this paper has further studied the application of bryophytes in landscape design and the match with other landscape elements.

\section{THE LANDSCAPE DESIGN PRINCIPLES OF BRYOPHYTES}

\section{A. The Scientific Principle}

The scientific principle is one of the most important principles in all plant design. If there is no scientific data and guidance, we will encounter many problems in the late growing process. For example, in selection of bryophyte species, cultivate waterside living bryophytes in relative dry urban garden. And then the later maintenance will cost a lot of energy and money, and even these bryophytes likely cannot survive or grow worse. This is why this paper carried out the bryophyte design research on the basis of microenvironment experiment of bryophytes.

Therefore, first we should ensure the survival of bryophytes in configuration, and then play its functions and effects. The previous researches showed that rock, woodland and sparse woodland lawns are microhabitats suitable for the growth of the bryophytes. Therefore, in similar regions, we can consider providing such microhabitat for bryophytes.

\section{B. The Cultural Principle}

In accordance with the requirements of today's society, the plant landscaping can usually reflect people's colorful material and cultural world. Chinese classic garden is often referred to as the literati garden. This is because scholars tend to closely combine poetic landscaping with and literary techniques. So, they regarded traditional culture as one ideological basis of plant landscaping.

In the summary of the art values of the bryophytes, it involves the film value, music value and literature value of bryophytes. These are parts of the cultural value. Under the influence of these poems, it can also provide basis for creating the special cultural atmosphere for bryophytes. Therefore, in the design of bryophyte landscape, we shall pay attention to the cultural principle of plant planting, and improve the spiritual connotation of the plant configuration.

\section{The Artistic Principle}

The garden design cannot be separated from the art form beauty of plants. The isolated planting, coupled planting, mass planting and group planting and other planting modes are all configurated according to the art structure principles of unity and change, harmony and contrast, balance, rhyme and rhythm and so on. For example, the roadside trees are the best illustration of unity and change. Many roadside trees keep consistent in selection of species and spacing distance. And add some bushes to increase the change of state and interestingness. It can ensure the general stability and make the whole landscape flexible. Music has the sense of rhyme and rhythm, because it has its internal law. The regular change of plant configuration also can produce a sense of rhythm. The configuration of bryophytes should also follow these artistic principles. For example, plant three small pieces of bryophyte communities on three rocks in different heights. The largest bryophyte community is close to the smallest community, and the middle community is relative far to the largest and the smallest communities. The three communities form an inequilateral triangle on the plane layout, seeking stability in asymmetry. 


\section{The ANALYsis AND COMPOSITION Of THE BRYOPHYTES IN THE GARDEN DESIGN}

\section{A. The Dot, Line, Plane And Bulk in Landscape Design}

The image of dot: the dot is a relative concept to plane in the formation picture. It has a certain area but no direction. Many dots together can produce a sense of line and plane. It is the most basic element. A single dot has the function of attracting sights. The image of line: line has length and direction in the picture composition. There are straight line, broken line and curve. In general, it is often considered that a straight line gives us a regular sense and a sense of strength. The broken line gives us a fresh sense, and curve gives us a soft and graceful sense. In landscape design, line often has depth. And we often use line to guide the sight and action line of tourists. The image of plane: plane has width and length, and its area can be calculated. There are many kinds of planes. In landscape design, a square pool is a plane; a circular pavement is also a plane; and a variety of irregular lawns are also planes. The image of bulk: bulk has area and depth, leaving people a steady and dignified impression. We can see and touch. In landscape design, landscape stone is a significant representative of bulk.

\section{B. Using the Bryophyte As Dot}

In natural condition, at the edge or in joint of cement road, or in the joints of slabstone often grow some bryophytes. Under the background of large area of hard pavement, the touch of green bryophytes exists as a dot. So, in the future design, in order to simulate the natural scene, we can add some dotted bryophytes on the basis of cement pavement, as shown in "Fig. 1" and "Fig. 2".

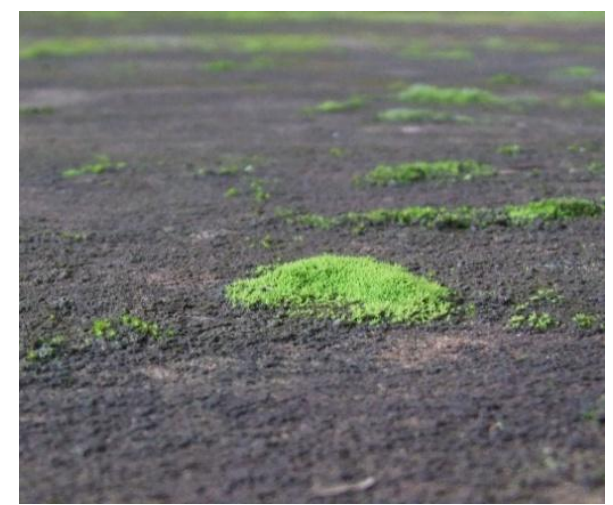

Fig. 1. Dotted bryophytes on the road

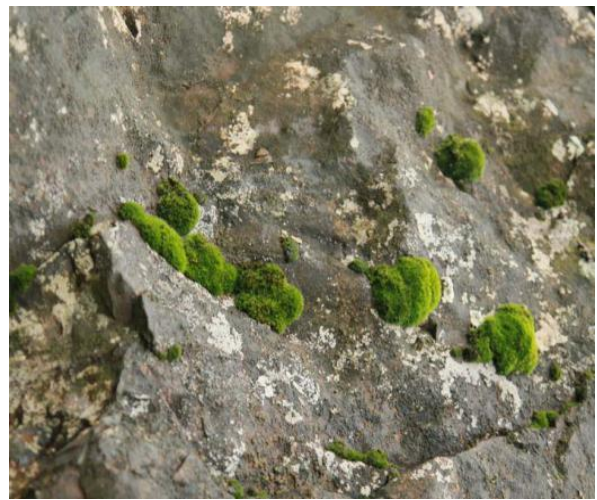

Fig. 2. Dotted bryophytes on the slope

\section{Using Bryophytes As Line}

In field landscaping, we can choose to use the bryophytes as spatial boundary suggestions. At this time, bryophytes usually are used as the edge of main landscape and a boundary line. For example, use appropriate bryophytes to decorate the edge of flower nursery. When you walk into a small garden, the whole land is covered with flowers and herbaceous plants with no exposed earth. If take a look at it, the lawn and flower planting have clear contours. It will be more attractive. Many defective areas can be covered with bryophytes, so as to divert the attention of visitors.

The linear bryophytes mainly have the function of defining the space. The definition of space is soft and suggestive. It is unlike fences that forcibly divide the rest space and the playground, and don't allow visitors to pass. When use linear bryophytes to divide space, it gives suggestions to visitors. Naturally it divides space for different purposes. There are many species of bryophytes. They are clear and vibrant in appearance, and bright green or dark green in color. Their small form is not easy to attract people's attention. But they can create comfortable visual experience and draw clear space outline, rather than stealing the show of some main flowers "Fig. 3" and "Fig. 4".

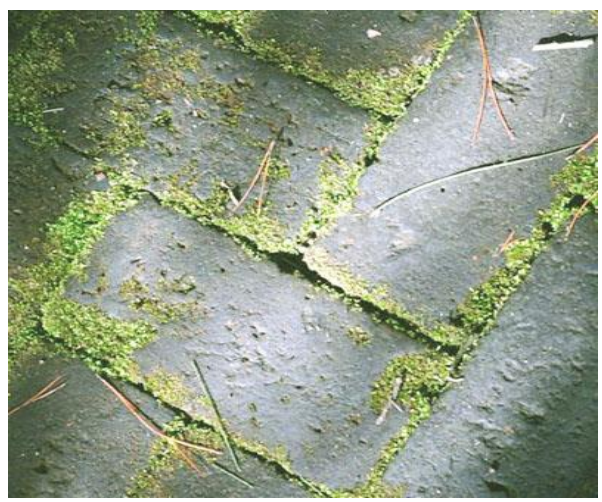

Fig. 3. Linear bryophytes in the joints of slabstone 


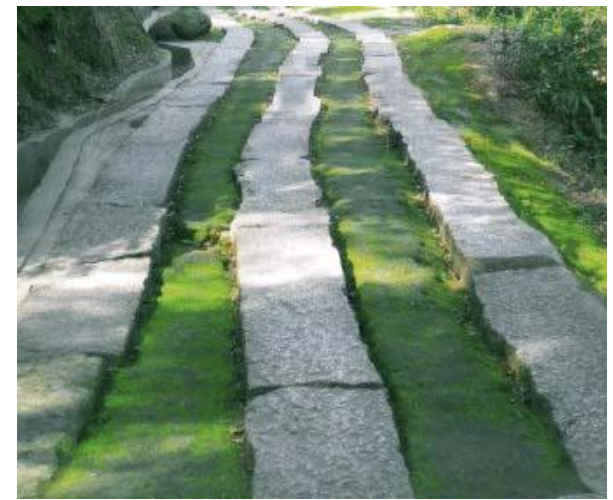

Fig. 4. Linear bryophytes along the road

\section{Using Bryophytes As Plane}

Surrounded by the Eurasian continent and the North American continent, the Arctic Ocean is covered with a large area of tundra, like a carpet covering the whole place. The large area can be up to dozens of hectares, becoming a wonder of the world. There are forest tundra, shrub tundra and lichen tundra. In this place, tundra exists as a plane. The trees and shrubs exist as dot, which is very shocking, as shown in "Fig. 5 ".

In plant configuration and design, the bryophytes can be cultivated in a large area like lawn, forming uniform carpetlike landscape to beautify environment and decorate land, as shown in "Fig. 6".

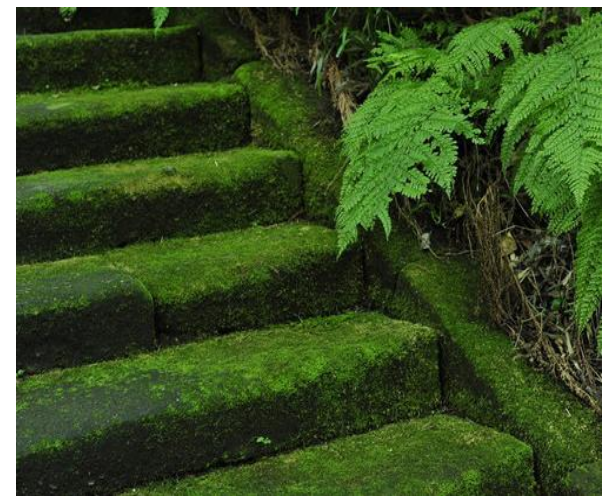

Fig. 5. Stepped planar bryophytes

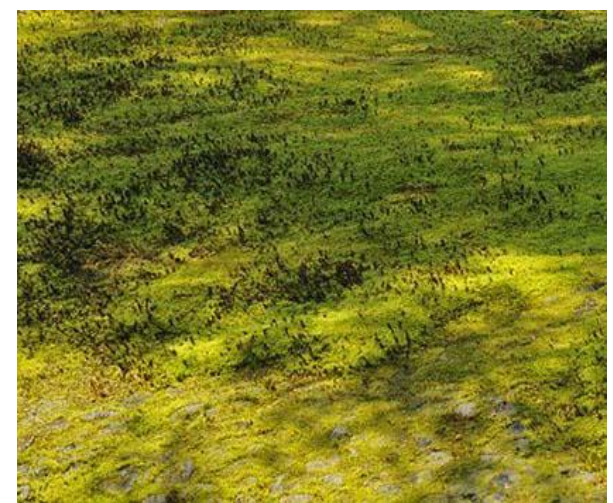

Fig. 6. Planar bryophytes under the trees

\section{E. Using Bryophytes As Bulk}

The bulk form of bryophytes usually is matched with different species of bryophytes and small sculptures or rocks in order to construct a garden landscape. In generally, they are endowed with different cultural meanings and symbolic meanings.

The landscaping match shall consider the proper match of different species and land, and the harmony and unity of bryophyte and rock environment. We often use rock and other garden elements, or beautiful small trees and flowering shrubs around as match materials. The bryophytes growing on rocks in sunny environment shall be drought-resist and alkali-resist, and be adapted to all sunny environments. The bryophytes matching with rocks generally are polytrchum commune, dicranum scoparium and etc.. The match of bryophytes and rocks is often used to decorate the axe marks of rocks, at same time, improve the layering sense of rock landscape and show the beauty of rock form, as shown in "Fig. 7" and "Fig. 8".

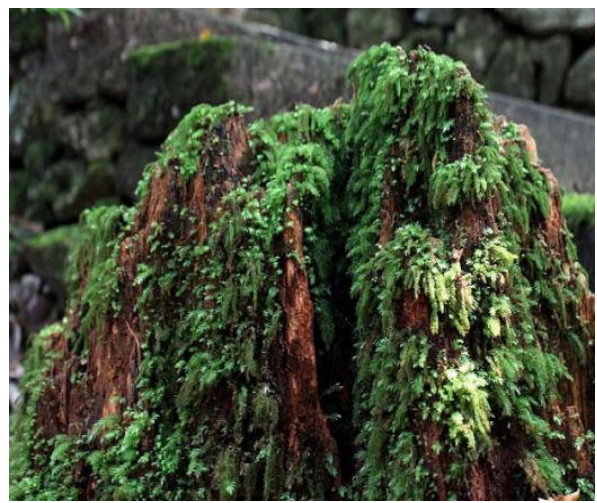

Fig. 7. The match of dead trees with bryophytes

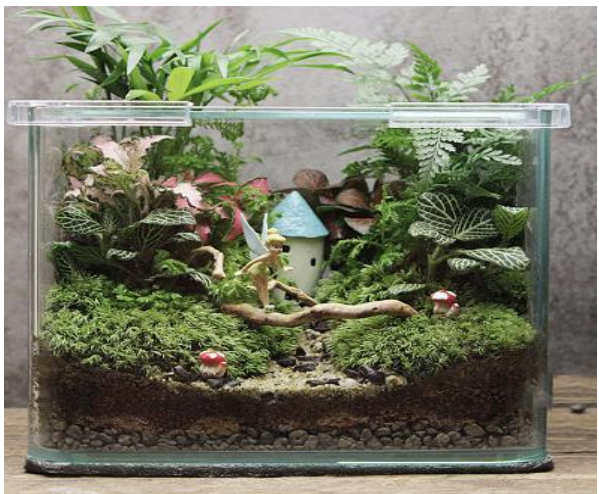

Fig. 8. Bryophyte micro-landscape

\section{THE MATCH OF BRyOPHYTES With OTHER GARDEN ELEMENTS}

\section{A. The Match of Bryophytes with Other Plants}

A lot of bryophytes are epiphytic plants, such as, bryum capillare, haplohymenium triste, hypnum plumaeforme, entodon compressus, and brachythecium nakazimae. A lot of them have the ornamental value, and can be used in landscape 
design. Of course, these bryophytes are usually of strong drought resistance and of strong human disturbance resistance.

In the previous studies, we found that willow, pterocarya stenoptera, ginkgo and camphor have epiphytic phenomena. Juratzkaea sinensis often attaches to camphor; entodon compressus to pterocarya stenoptera; and entodon compressus to ginkgo. We found that no epiphytic bryophyte species is particular about willow. Therefore, we shall use specific trees if we use juratzkaea sinensis, entodon compressus and other bryophytes. Willow is suitable for the vast majority of epiphytic bryophytes, so we can extensively use willow in designing bryophyte landscape.

In the creation of large bulk form of epiphytic bryophytes landscape, in order to let the bryophytes but the trunk itself cause the attention of people, we should pay attention to the following points:

(1) The height of the bryophytes shall be controlled in the range of $1.4 \sim 1.6 \mathrm{~m}$. It is the horizontal line of human's eye sight. It enables people to see designers' carefully designed bryophyte landscape in normal eye sight.

(2) In order to ensure the good growth of bryophytes, we should cultivate them at the backlight side of trunks.

(3) We should choose bright-colored epiphytic species of bryophytes to create a green effect.

The above describes the construction methods of epiphytic bryophytes. Below we will talk several land planting modes of bryophytes. The first mode is to match bryophytes with zoysia japonica and tall trees to create the effect of sparse woodland lawn. If match bryophytes with zoysia japonica, the bryophytes can grow vigorously and completely cover the land, and form a compact carpet effect. The second mode is to match bryophytes with tall trees and shrubs with compact branches and leaves. For tall trees, we can use ficus virens, camphor, and sweet-scented osmanthus trees. For shrubs, we can use rhododendron and ligustrum lobule, as shown in "Fig. 9 " and "Fig. 10".

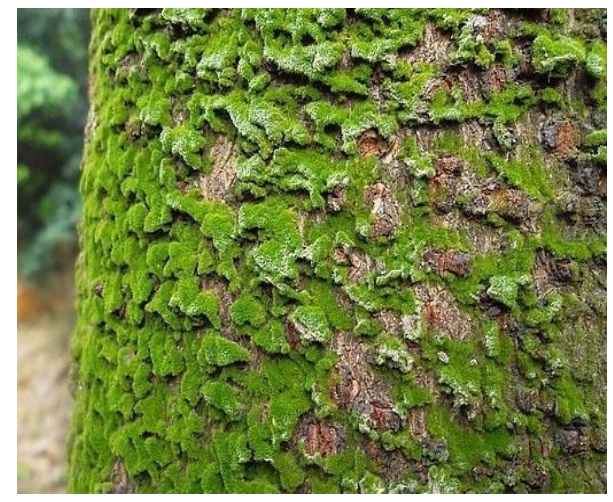

Fig. 9. Bryophytes attached to salicaceae plants

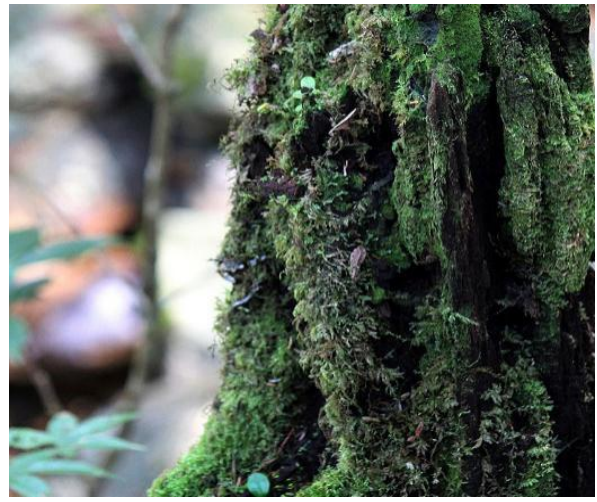

Fig. 10. Bryophytes attached to pinaceae plants

\section{B. The Match of Bryophytes with Bryophytes}

In the process of research, the author found that all kinds of bryophytes crowded together, with a high ornamental value. First, most of bryophytes are green. But the green degrees of each bryophyte are different. There are emerald green, dark green, olive green, light green, sage green, yellow green and so on. So, the match of bryophytes will be simple and harmonious. The first main point for match of bryophytes is that the habitats of bryophytes shall be same or similar. The second main point is that it is necessary to leave some development space for bryophytes in cultivation. The third main point is to consider the ornamental value of match of bryophytes.

After investigation, the author found that liverworts, funaria hygrometrica and polytrichum commune could grow together at will in Chengdu Wenjiang Park. Polytrichum commune, funaria hygrometrica and leucobryum neilgherrense often live together, and their shades of colors are varied and different, and forms are also different. In the two match modes, we can select any one bryophyte as main subject or as a "plane". The second bryophyte can be cultivated on a higher landform behind the main bryophyte, as "bulk". The rest bryophyte can be inserted on the "plane" and "bulk" as "dot" in order to animate the whole atmosphere in steady and uniform bryophyte composition. The above are recommended bryophyte communities and configuration plans after field investigation. If bryophyte designers want more plentiful species choices, they can select from bryophyte stores. The better way is to choose a species of bryophyte with a high ornamental value as main subject, and then match other species of different texture, color and form, as shown in "Fig. 11 " and "Fig. 12". 


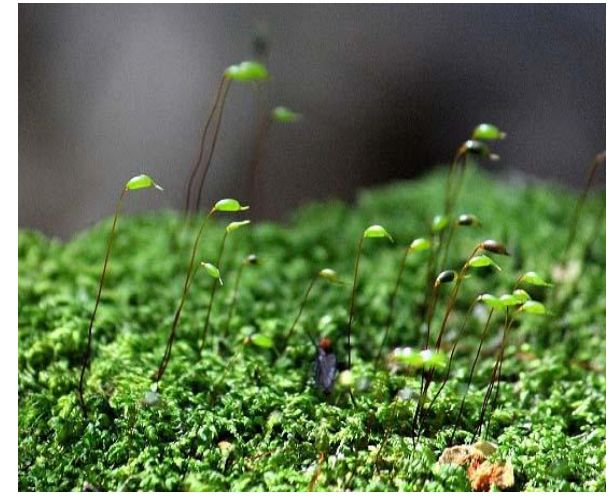

Fig. 11. Match of different forms

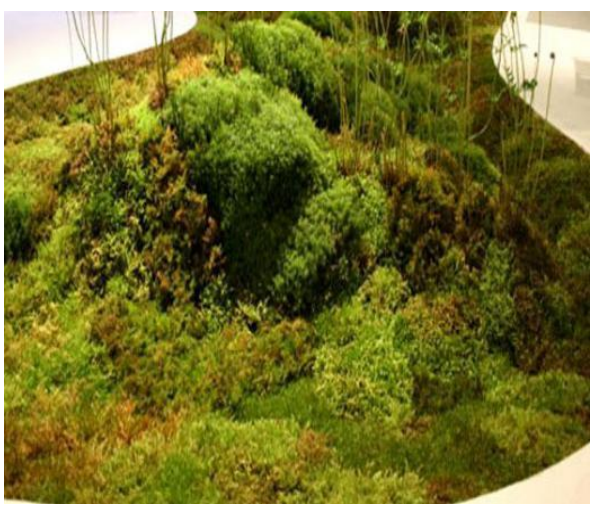

Fig. 12. Match of different colors

\section{The Match of Bryophytes with Garden Ornaments}

Many species of bryophytes can grow on stones, such as aerobryum speciosum, wijkia hornschuchii, anomobryum auratum, anomobryum gemmigerum and barbulaunguiculata. Thus, if we want to associate bryophytes with garden ornaments, it is necessary to consider the materials for garden ornaments. Through investigation, the author found that rocks easily get weathered and has high content of organic matters is more suitable for the growth of bryophytes. Thus, it is suggested to use relative soft and easily weathered rock materials if want to show a Japanese-style garden, and a solitary sense with moss covering stone lanterns.

Some other bryophytes prefer rot wood materials, such as pseudobarbella levieri, oncophorus crispifolius, leucobryum bowringii, haplohymenium pseudo-triste and gymnostomum recurvirostre. Therefore, we can use rot wood and bryophytes to create a special bryophyte landscape to express a sense of history "Fig. 13" and "Fig. 14".

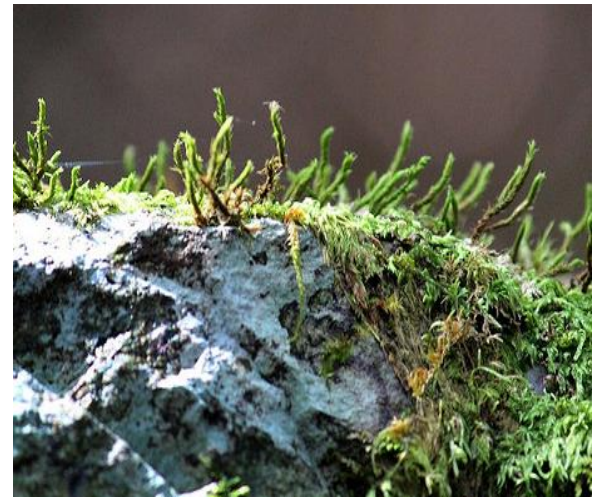

Fig. 13. Bryophytes and rock landscaping

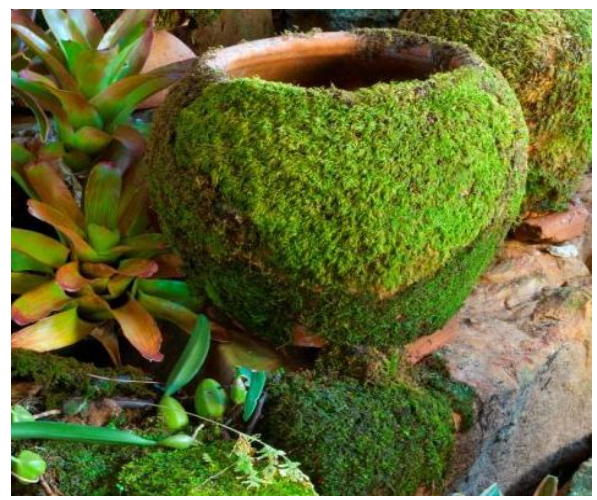

Fig. 14. Bryophytes and small garden ornaments

\section{REFERENCES}

[1] Zhang Zheng. Study on Species Diversity and Distribution Pattern of Bryophytes in Jiangsu Wuxi. Shanghai Normal University, 2006.

[2] Zheng Min. Research of Chinese Hepatophyta Chromosome. East China Normal University, 2007.

[3] Xiong Xin Yuan, Pan Yu. Rare and Endangered Bryophytes in Guizhou Province, China, Guizhou Science, 2007, 25 (2): 68-71.

[4] Shi Ruiping. The Species Diversity and Distribution of Hepaticae and Anthoceratae. East China Normal University, 2008.

[5] Wang Jian, Cao Tong, Wang Min. Diversity and Characteristics of Bryophytes in Suzhou Garden. Journal of Northwest China, 2007, 27 (6): 1239-1246.

[6] Jiao Yunhong, Ye Jia. Analysis of Application of Bryophytes in Garden City Construction. Journal of Biology, 2006, 23 (2): 45-49, 34.

[7] Zhou Zhijing, Zhu Yalan, Ding Shaogang. Bryophytes and Application in Garden. Chinese Urban Forestry, 2009, 7 (1): 21-23.

[8] Chen Junhe, Jiang Ming, Zhang Li. Analysis of the Application of Bryophytes in Garden Landscape. Guangdong Garden, 2010, 32 (1): 31 34.

[9] Chen Bangjie. Bryophytes in China. Beijing: Science Press, 1963.

[10] Wang Qing, Zhang Guangning, He Shan'an. Application Prospect of Bryophytes in Garden. Chinese Garden, 1999, 15 (6): 25-26.

[11] Chen Binghong, Chen Qiaobiao, Li Qiuping. Functional Analysis of Bryophytes and Garden Product Development. Northern Horticulture, 2013 (8): 90-93.

[12] Sun Junfeng. Propagation and Cultivation Methods of Bryophytes and Values of Specialized Bryophyte Garden. Modern Gardens, 2013, 10 (11): 63-68. 